\title{
AS PESQUISAS DENOMINADAS "ESTADO DA ARTE"
}

\author{
Norma Sandra de Almeida Ferreira*
}

\begin{abstract}
RESUMO: Nos últimos quinze anos, no Brasil e em outros países, tem se produzido um conjunto significativo de pesquisas conhecidas pela denominação "estado da arte" ou "estado do conhecimento". Definidas como de caráter bibliográfico, elas parecem trazer em comum o desafio de mapear e de discutir uma certa produção acadêmica em diferentes campos do conhecimento, tentando responder que aspectos e dimensões vêm sendo destacados e privilegiados em diferentes épocas e lugares, de que formas e em que condiçôes têm sido produzidas certas dissertações de mestrado, teses de doutorado, publicaçōes em periódicos e comunicaçōes em anais de congressos e de seminários. Neste artigo levanto e tento responder as seguintes questôes: seria possível fazer um esforço de interrogar a história a produção acadêmica sobre determinada área do conhecimento, optando por ler apenas dados bibliográficos e resumos dos trabalhos? O que significa ler esse lugar (catálogos), instituição de divulgação dos trabalhos, tomando-o como fonte documental para um mapeamento da produção acadêmica, em pesquisas denominadas "estado da arte"?
\end{abstract}

Palavras-chave: Estado da arte. Mapeamento. Produção acadêmica.

\section{ResearCh Called "STATE OF THE ART"}

ABSTRACT: These last fifteen years, Brazil and other countries have seen the production of a significant set of research, known as "state of the art" or "state of knowledge". Defined as having a bibliographic feature, they seem to share the challenge of mapping and discussing a certain academic production in different fields of knowledge. They try to show which aspects and dimensions have been highlighted and privileged at different times and places. They also pinpoint how and in what conditions certain kinds of master's degree thesis and doctor's degree dissertations, publications in periodicals and communications

Professora do Departamento de Metodologia de Ensino (DEME) e pesquisadora do grupo de pesquisa Alfabetização, Leitura e Escrita (Alle) da Faculdade de Educação da UnicAmp. E-mail: normasandra@aol.com.br 
in annals of congress and seminary were produced. In this article, I pose and try to answer the following questions: Is it worth making the effort of interrogating the history of the academic production about a given area of knowledge, choosing to read only bibliographic data and abstracts of works? What does it man to read this institution of work dissemination (catalogues), taking it as a documental source to map the academic production in research called "state of art"?

Key words: State of art. Mapping. Academic production.

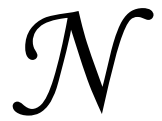

os últimos quinze anos tem se produzido um conjunto significativo de pesquisas conhecidas pela denominação "estado da arte" ou "estado do conhecimento". Definidas como de caráter bibliográfico, elas parecem trazer em comum o desafio de mapear e de discutir uma certa produção acadêmica em diferentes campos do conhecimento, tentando responder que aspectos e dimensões vêm sendo destacados e privilegiados em diferentes épocas e lugares, de que formas e em que condições têm sido produzidas certas dissertações de mestrado, teses de doutorado, publicações em periódicos e comunicações em anais de congressos e de seminários. Também são reconhecidas por realizarem uma metodologia de caráter inventariante e descritivo da produção acadêmica e científica sobre o tema que busca investigar, à luz de categorias e facetas que se caracterizam enquanto tais em cada trabalho e no conjunto deles, sob os quais o fenômeno passa a ser analisado.

Tomando como referência o Brasil, podemos citar como exemplos, entre outros tantos, os trabalhos intitulados como "estado da arte", tais como: Alfabetização no Brasil - o estado do conhecimento (Soares, 1989); Rumos da pesquisa brasileira em Educação Matemática: o caso da produção científica em cursos de pós-graduação (Fiorentini, 1994); Tendências da pesquisa acadêmica sobre o ensino de ciências no nivel fundamental (Megid, 1999); Pesquisa em Leitura: um estudo dos resumos e dissertaçôes de mestrado e teses de doutorado defendidas no Brasil, 1980 a 1995 (Ferreira, 1999); Estado da arte sobre formação de professores nas dissertaçôes e teses dos programas de pós-graduação das universidades brasileiras, 1990 a 1996 (André e Romanowski) e Estado da arte sobre a formação de professores nos trabalhos apresentados no GT 8 da Anped, 1990-1998 (Brzezinski e Garrido, 1999).

\section{$\mathrm{O}$ que move esses pesquisadores?}

A sensação que parece invadir esses pesquisadores é a do não conhecimento acerca da totalidade de estudos e pesquisas em determinada 
área de conhecimento que apresenta crescimento tanto quantitativo quanto qualitativo, principalmente reflexões desenvolvidas em nível de pós-graduação, produção esta distribuída por inúmeros programas de pós e pouco divulgada.

É assim que Soares, em Alfabetização no Brasil-O estado do conhecimento, ao buscar organizar pesquisas produzidas na área de Alfabetização, período de 1954 a 1986, justifica a relevância de trabalhos nessa natureza:

(...) a multiplicidade de perspectivas e pluralidades de enfoques sobre Alfabetização não trarão colaboração realmente efetiva enquanto não se tentar uma articulação das análises provenientes de outras áreas de conhecimento, articulação que busque ou integrar estruturalmente estudos e resultados de pesquisas, ou evidenciar e explicar incoerências e resultados incompatíveis. Um primeiro e indispensável passo nesse sentido é a revisão dessas perspectivas, análises e estudos, de modo que se possa ter uma visão de "estado de conhecimento" em nosso País, na área da Alfabetização: uma revisão crítica dos estudos e pesquisas sobre Alfabetização que se vêm multiplicando nas últimas décadas (...). (1982, p. 2)

Em outro momento de sua pesquisa, ela afirma que:

Essa compreensão do estado de conhecimento sobre um tema, em determinado momento, é necessária no processo de evolução da ciência, afim de que se ordene periodicamente o conjunto de informaçôes e resultados já obtidos, ordenação que permita indicação das possibilidades de integração de diferentes perspectivas, aparentemente autônomas, a identificação de duplicaçôes ou contradições, e a determinação de lacunas e vieses. $(1987$, p. 3$)$

Sustentados e movidos pelo desafio de conhecer o já construído e produzido para depois buscar o que ainda não foi feito, de dedicar cada vez mais atenção a um número considerável de pesquisas realizadas de difícil acesso, de dar conta de determinado saber que se avoluma cada vez mais rapidamente e de divulgá-lo para a sociedade, todos esses pesquisadores trazem em comum a opção metodológica, por se constituírem pesquisas de levantamento e de avaliação do conhecimento sobre determinado tema.

\section{Os catálogos como fonte documental}

Esses pesquisadores tomam como fontes básicas de referência para realizar o levantamento dos dados e suas análises, principalmente, os catálogos de faculdades, institutos, universidades, associações nacionais e órgãos de fomento da pesquisa. 
Nos últimos vinte anos, com o fortalecimento da produção acadêmica-científica, com pesquisas que emergem em diferentes programas de pós-graduação pelo país, um movimento se transforma em empenho de diferentes entidades (faculdades e associações de financiamento de pesquisas) para o estabelecimento de uma política de divulgação de seus trabalhos científicos. E uma das formas é através de catálogos, inicialmente impressos e, mais tarde, em forma de CD-ROM.

Os catálogos passam a ser produzidos atendendo ao anseio manifestado pelas universidades de informar sua produção à comunidade científica e à sociedade, socializando e, mais do que isso, expondo-se à avaliação. É um sentimento de que trabalhos produzidos ao longo dos anos não devem ficam restritos às prateleiras das bibliotecas das universidades.

Por outro lado, é uma resposta exigida por uma sociedade que vê a universidade como prestadora de serviços e que, por isso, deve ser avaliada. Segundo Chauí $(1999$, p. 6), a avaliação de toda e qualquer universidade passa a ser caracterizada por uma qualidade que traz como definição:

'qualidade' é definida como competência e excelência cujo critério é o atendimento às necessidades de modernização da economia e desenvolvimento social; e é medida pela produtividade, orientada por três critérios: quanto uma universidade produz, em quanto tempo produz e qual o custo do que produz. (...) Observa-se que a pergunta pela produtividade não indaga o que se produz, como se produz, para quem ou para que se produz, mas opera uma inversão tipicamente ideológica da qualidade em quantidade.

A universidade, segundo a autora, deixa de ser instituição social para ser vista como organização social, definida por uma prática que se caracteriza pela instrumentalidade e cujo reconhecimento e legitimidade são definidos pela idéia de eficácia e sucesso (quantidade de resultados em curto espaço de tempo).

Portanto, é nessa conjuntura que os catálogos vêm atender tanto a anseios internos da universidade, quanto à pressão externa de uma política reguladora e controladora da produção científica.

Os catálogos são organizados pela idéia de acumulação - reunir tudo o que se tem de avanço da ciência em um único lugar; pelo fascínio de se ter a totalidade de informações - dominar um campo de produção de um conhecimento, visão absoluta de poder; pela possibilidade de otimização da pesquisa - ganhar tempo, recuperar velozmente informações, com menor esforço físico; pelo mito da originalidade do conhe- 
cimento - pesquisar o que não se conseguiu ainda, fazer o que ainda não foi feito; pela imagem de conectividade - estar informado com tudo que se produz em todos os lugares. Além disso, há várias outras razóes e estratégias de organização do catálogo: a disputa por verbas para bolsas, convênios estimulando certos estudos, o sentimento de poder das instituiçôes que o produzem, um markenting da própria pesquisa acadêmica que está colocada no mercado como qualquer outra mercadoria. Os catálogos fazem, portanto, parte da disputa política no interior dos Institutos de Ensino Superior.

De qualquer maneira, os catálogos se instalam criando condições para que maior número de pesquisadores interessados em temas afins estabeleçam um primeiro contato, recuperem determinado trabalho, possibilitando a circulação e intercâmbio entre a produção construída e aquela a construir.

Os catálogos permitem o rastreamento do já construído, orientam o leitor na pesquisa bibliográfica de produção de uma certa área. Eles podem ser consultados em ordem alfabética por assuntos, por temas, por autores, por datas, por áreas.

Os catálogos trazem os títulos das dissertações de mestrado e teses de doutorado, mas também os dados identificadores de cada pesquisa quanto aos nomes do autor e do orientador, do local, data da defesa do trabalho, da área em que foi produzido. Os dados bibliográficos são retirados das dissertaçôes de mestrado e das teses de doutorado para serem inseridos nos catálogos.

Os títulos que se referem às dissertações e às teses informam ao leitor do catálogo a existência de tal pesquisa. Normalmente, eles anunciam a informação principal do trabalho ou indicam elementos que caracterizam o seu conteúdo. Longe das prescrições, tal qual a de Severino (1976, p. 62): “Todos os títulos (...) devem ser temáticos e expressivos, ou seja, devem dar a idéia a mais exata possível do conteúdo do setor que intitulam".

Os autores criam diferentes títulos para diferentes gostos. Nos catálogos há títulos curtos, longos, densos, subjetivos. Há títulos seguidos de ponto final (a maioria), mas também os acompanhados por interrogações, e até por reticências.

Com o catálogo, com a possibilidade de divulgação ampla, atingindo lugares fora da própria universidade produtora, atingindo maior número de leitores, surgem novas relações de produção e de consumo. O catálogo precisa se tornar mais complexo para atender a uma comunidade de pesquisadores mais exigentes, desejosos de mais 
informações antes de optar pela leitura do original. Criadas novas perspectivas na produção e consumo desse material de consulta, constatase que não bastam as referências limitadas ao registro dos principais dados indicadores: título do trabalho, nomes do autor e do orientador, local e data de defesa, titulação dada, como foram organizados os primeiros catálogos.

O resumo é, então, incluído com a finalidade de divulgar com mais abrangência os trabalhos produzidos na esfera acadêmica. Assim, escreve Garrido (1993, p. 5), na apresentação do Catálogo do Instituto de Psicologia da USP:

Além da indicação bibliográfica de cada trabalho, acrescentou-se um resumo, de caráter informativo, para promover a divulgação e facilitar o acesso a esses estudos. $\mathrm{O}$ crescimento da literatura científica transformou os resumos em instrumentos indispensáveis, na medida em que sua inserção em catálogos e bases de dados agiliza, em muito, a atividade de seleção em busca bibliográfica de todos aqueles que se dedicam ao estudo e à pesquisa. Para que desempenhem este importante papel é necessário, no entanto, que sejam objeto de elaboração cuidadosa.

Em seguida, Garrido prescreve o que deve constar em cada resumo para sua inclusão no catálogo: o objetivo principal de investigação; a metodologia/procedimento utilizado na abordagem do problema proposto; o instrumento teórico, técnicas, sujeitos e métodos de tratamento dos dados; os resultados; as conclusōes e, por vezes, as recomendaçôes finais.

\section{Os resumos das dissertações e teses nos catálogos}

E os resumos, de onde vêm? Estão no corpo dos próprios trabalhos? São produtos da elaboração dos organizadores dos catálogos?

A história da pesquisa acadêmica revela que as primeiras dissertações de mestrado e teses de doutorado produzidas na década de 1970 e na primeira metade da de 1980 raramente traziam o resumo como texto autônomo que apresentasse o trabalho. Há caso encontrado, por exemplo, do resumo estar junto com as conclusões do trabalho, como o de Garrido (1979), que aponta o quinto e último capítulo de sua dissertação com o título "Resumo e Conclusões". Na fase de amadurecimento da produção acadêmica, torna-se mais freqüente encontrar o resumo no interior do trabalho. Assim, o resumo vincula-se a uma série de dispositivos de escrita e impressão (capa, título, página de rosto, índice, dedicatória, agradecimentos, a pesquisa em si, bibliografia) de cada dissertação ou tese que o coloca como um a mais entre outros (dispositivos). 
Os resumos, quando não são encontrados nas próprias pesquisas, desencadeiam diferentes práticas no momento de produção de um catálogo. Há casos em que os organizadores dos bancos de dados optam por colocar apenas os dados bibliográficos de determinada pesquisa. Também os produtores dos catálogos podem elaborar resumos segundo critérios pré-estabelecidos para aquelas dissertações ou teses a que eles não tiveram acesso ou que não trazem esse texto no interior do trabalho. Há ainda outros que fazem revisóes e reescritas dos resumos produzidos pelo próprio autor do trabalho, buscando a homogeneidade e consistência do todo do Catálogo, como, por exemplo, o da "Universidade Federal Fluminense, 1975 - 1995" (1996, p. 7):

Para garantir que os dados fossem apresentados de forma correta e completa, a versão original apresentada pelos próprios mestrandos ou encontradas no corpo das dissertaçōes nem sempre foi mantida. Os resumos foram elaborados, revisados e reunidos especialmente para o catálogo e seguiram critérios definindo o limite de linhas e determinando os elementos informativos mais relevantes.

Vê-se que muitas vezes o próprio autor da dissertação ou da tese torna-se também autor de vários resumos, atendendo às exigências de seu programa de Pós-Graduação. Um, que é o que constará em uma das primeiras páginas de sua pesquisa; outro que acompanhará o formulário da ANPED (para aqueles que estão inscritos nos programas ligados à Educação); e ainda, aquele que cumpre às solicitações da CAPES. Para cada um deles, diferentes exigências quanto ao número de linhas, tamanho das letras, o que deve constar etc.

No caso dos catálogos informatizados, produto do desenvolvimento da rede eletrônica, na maioria das vezes, os seus resumos são reproduçóes dos impressos, porém podem trazer mudanças tipográficas (o espaço do parágrafo desaparece, orações são juntadas num mesmo período, diminuise o tamanho das letras, encurta-se o espaço entre parágrafos); ou de extensão (cortam-se linhas, palavras, parágrafos, tira-se o final), ou, ainda, de adaptações (palavras são substituídas por sinônimos, há acréscimos de termos): exigências do novo suporte.

$\mathrm{Na}$ realidade, os resumos mostram uma rede de motivos implicada em operaçóes de selecionar e organizar o material a ser divulgado, que os tornam diversificados e multifacetados, resultados de diferentes operaçóes (cortes e acréscimos) feitas a muitas mãos, por diferentes motivos totalmente desconhecidos do leitor. 
O que temos, então, ao assumirmos os resumos das dissertações e teses presentes nos catálogos como lugar de consulta e de pesquisa, é que sob aparente homogeneidade, há grande heterogeneidade entre eles (os resumos) explicável não só pelas representações diferentes que cada autor do resumo tem deste gênero discursivo, mas também por diferenças resultantes do confronto dessas representaçóes com algumas características peculiares da situação comunicacional, como alterações no suporte material, regras das entidades responsáveis pela divulgação daquele resumo, entre outras várias.

Há resumo mais enxuto, menor e com uma configuração mais padronizada do gênero a que pertence, que parece ter sido orientado pelo suporte material em que aparece (CD-ROM, por exemplo), e/ou ainda, pelo fato de estar sendo divulgado por uma instituição de caráter nacional, responsável pela divulgação de uma maior quantidade de pesquisas (ANPED). Há resumos com características típicas de uma narrativa (narrar o percurso do narrador, narrador do tipo $1^{\text {a }}$ pessoa, mais caracterização dos sujeitos pesquisados), que sugerem uma certa relação estabelecida entre o autor e a própria pesquisa.

Há resumos diferentes de uma mesma pesquisa que revelam intervenções de ordem tipográfica/impressão quando produzidos no interior de uma tese de doutorado ou dissertação de mestrado, quando em catálogo impresso ou eletrônico produzido pelas universidades ou associaçōes e entidades (ANPED, UNIBIBLI, UFSCAR). Há mudanças tipográficas e textuais dos resumos em CD-ROM de entidades nacionais (supressão de parágrafos, cortes de frases e palavras etc.), em relação aos resumos que estão no interior da própria pesquisa, guiadas pelo leitor pressuposto do texto. ${ }^{1}$

Essas diferenças, singularidades entre resumos de uma mesma pesquisa e entre os que formam o conjunto do corpus de um determinado catálogo, são explicadas pela maleabilidade e pela relativa estabilidade do gênero, pela possibilidade de alteração que cada gênero oferece de acordo com as necessidades, interesses e condições de funcionamento dos grupos sociais que o utilizam e, no caso, de um autor particular em uma dada situação comunicacional.

É possível traçar um determinado "estado da arte" lendo apenas resumos?

Se estamos pensando em utilizar como objeto de estudo e como fonte de pesquisa - os resumos - nos trabalhos intitulados "estado da arte" ou "estado do conhecimento", se estamos entendendo que os resumos que constam nos catálogos estão atendendo a outras funções e necessidades; 
se estamos aceitando a heterogeneidade de marcas textuais e tipográficas constatadas nos resumos; podemos considerar possível tecer um discurso que analise, interrogue, explique convenientemente cada conjunto de trabalhos produzidos em uma determinada área do conhecimento, a partir apenas de resumos, ignorando a leitura das pesquisas, na íntegra?

Quando se trata de utilizar como fonte de pesquisa os catálogos com dados bibliográficos e resumos dos trabalhos produzidos na academia para uma possível organização da produção de uma certa área do conhecimento, parece que o pesquisador do "estado da arte" tem dois momentos bastante distintos.

Um, primeiro, que é aquele em que ele interage com a produção acadêmica através da quantificação e de identificação de dados bibliográficos, com o objetivo de mapear essa produção num período delimitado, em anos, locais, áreas de produção. Nesse caso, há um certo conforto para o pesquisador, pois ele lidará com os dados objetivos e concretos localizados nas indicações bibliográficas que remetem à pesquisa. Ele pode visualizar, nesse momento, uma narrativa da produção acadêmica que muitas vezes revela a história da implantação e amadurecimento da pós-graduação, de determinadas entidades e de alguns órgãos de fomento à pesquisa em nosso país. Nesse esforço de ordenação da uma certa produção de conhecimento também é possível perceber que as pesquisas crescem e se espessam ao longo do tempo; ampliam-se em saltos ou em movimentos contínuos; multiplicam-se, mudando os sujeitos e as forças envolvidas; diversificamse os locais de produção, entrecruzam-se e transformam-se; desaparecem em algum tempo ou lugar.

Um segundo momento é aquele em que o pesquisador se pergunta sobre a possibilidade de inventariar essa produção, imaginando tendências, ênfases, escolhas metodológicas e teóricas, aproximando ou diferenciando trabalhos entre si, na escrita de uma história de uma determinada área do conhecimento. Aqui, ele deve buscar responder, além das perguntas "quando", "onde" e "quem" produz pesquisas num determinado período e lugar, àquelas questôes que se referem a "o quê" e "o como" dos trabalhos.

Nessa segunda opção, o pesquisador passa a enfrentar dificuldades inúmeras e de diferentes ordens. A organização do material que tem diante de si pressupõe antes de tudo uma leitura que ele deve fazer não só das indicaçōes bibliográficas e dos títulos dos trabalhos, mas principalmente dos resumos. E há sempre a sensação de que sua leitura a partir apenas dos resumos não lhe dá a idéia do todo, a idéia do que "verdadei- 
ramente" trata a pesquisa. Há também a idéia de que ele possa estar fazendo uma leitura descuidada do resumo, o que significará uma classificação equivocada do trabalho em um determinado agrupamento, principalmente quando se trata de enquadrá-lo quanto à metodologia, teoria ou mesmo tema. Por outro lado, há também a sensação de que os resumos encontrados nos catálogos são mal feitos, cortados, recortados por "n" razões, sem autoria definida e de difícil acesso. Por último, ao se constatar a existência de mais de um resumo para um mesmo trabalho e, além de tudo, diferentes entre si (no suporte material do texto; nas disposições tipográficas; nas informações que apresentam), institui-se o conflito de qual resumo responderá melhor às questões a que se propõe investigar. E passa-se a "avaliar" qual é o resumo mais "correto", completo e coerente com o trabalho "original", isto é, integral.

Para essas dificuldades, alguns pesquisadores do "estado da arte" acabam tomando posiçôes diversas: alguns lidam com um certa tranqüilidade no mapeamento que se propóem a fazer da produção acadêmica a partir dos resumos publicados em catálogos das instituições, ignorando todas essas limitações que o próprio objeto oferece; outros optam por uma única fonte, por exemplo, os resumos encontrados na ANPED; e há ainda aqueles que, num primeiro momento, acessam as pesquisas através dos resumos e, em seguida, vão em busca dos trabalhos na íntegra. Megid (1999), por exemplo, em sua tese de doutorado questiona as pesquisas identificadas como do "estado da arte", baseadas na leitura e análise dos resumos publicados em catálogos das instituições. Assim diz ele:

Toda essa discussão tem por objetivo expressar algumas limitações dos catálogos ou bancos de dados sobre a produção acadêmica, no que se refere a uma divulgação adequada da mesma. Os dados bibliográficos dos trabalhos já permitem uma primeira divulgação da produção, embora bastante precária. Os resumos ampliam um pouco mais as informaçôes disponíveis, porém, por serem muito sucintos e, em muitos casos, mal elaborados ou equivocados, não são suficientes para a divulgação dos resultados e das possíveis contribuições dessa produção para a melhoria do sistema educacional. Somente com a leitura completa ou parcial do texto final da tese ou dissertação desses aspectos (resultados, subsídios, sugestôes metodológicas etc) podem ser percebidos. Para estudos sobre o estado da arte da pesquisa acadêmica nos programas de pós-graduação em Educação, todas essas formas de veiculação das pesquisas são insuficientes. É preciso ter o texto original da tese ou dissertação disponível para leitura e consulta.

De qualquer maneira, as opções desses pesquisadores nos levam a questionar a natureza do material com o qual temos trabalhado: os resumos. É possível afirmar o que se tem falado sobre determinado tema ou 
área de conhecimento, em nosso país, num certo período, a partir só da leitura dos resumos? Um resumo poderia ser lido como parte de um todo? Que relação poderia ser feita entre cada resumo e o trabalho que lhe deu origem? É possível um olhar metonímico para cada resumo?

Buscando respostas para essas interrogaçooes, entre outras saídas já encontradas por outros pesquisadores, enveredamos por uma: levar em consideração a natureza do material que temos em mãos a partir da noção de gênero do discurso, conforme Bakhtin (1997) e da noção do suporte material em que cada resumo se apresenta, de acordo com Chartier (1990, 1996).

Ancorando-nos em Bakhtin (1997), podemos ler cada resumo como um dos gêneros do discurso ligado à esfera acadêmica, com determinada finalidade e com certas condições específicas de produção. Cada resumo é lido como um enunciado estável delimitado pela alternância dos sujeitos produtores, pela noçãa de acabamento de todo e qualquer enunciado e pela relação dos parceiros envolvidos em sua produção e recepção. Enquanto gênero do discurso, cada resumo é lido pelos elementos que o constituem (conteúdo temático, estilo verbal e estrutura composicional), fundidos no todo que é o enunciado. Por outro lado, assumindo o princípio de dialogismo de Bakhtin, cada resumo é lido como participante de uma cadeia de comunicação verbal, onde suscita respostas e responde a outros resumos.

Com Chartier (1990, 1996) há uma maneira de ler os resumos a partir do suporte material que os abrigam (CD-ROM, catálogo impresso, resumo na própria tese), interrogando-os não só como textos, mas como objeto cultural. Um objeto cultural criado para satisfazer uma finalidade específica, para ser usado por certa comunidade de leitores; que propóe maneiras diferentes de lê-lo; que obedece a certas convençôes, normas relativas ao gênero do discurso, ao suporte material em que se encontra inscrito e às condições específicas de produção.

\section{O "estado da arte" e suas limitações}

Com essas preocupações, aqui de maneira breve e sucinta, desacompanhada das análises que possam contribuir para uma leitura melhor de alguns outros questionamentos, apresentamos algumas das conclusões a que chegamos, no mapeamento da História da Leitura no Brasil, no período de 1980 a 1995 (Ferreira, 1999), mas que acreditamos que possam sem estendidas a outras pesquisas do tipo "estado da arte". 
Ao lidarmos com um conjunto de resumos de uma certa área do conhecimento, buscando identificar determinadas marcas de convencionalidade deste gênero discursivo, podemos constatar que eles cumprem a finalidade que lhes está prevista em catálogos produzidos na esfera acadêmica: informam ao leitor, de maneira rápida, sucinta e objetiva sobre o trabalho do qual se originam.

Eles trazem, enquanto gênero do discurso, um conteúdo temático, que é o de apresentar aspectos das pesquisas a que se referem; trazem uma certa padronização quanto à estrutura composicional: anunciam o que se pretendeu investigar, apontam o percurso metodológico realizado, descrevem os resultados alcançados; e, em sua maioria, seu estilo verbal é marcado por uma linguagem concisa e descritiva, formada de frases assertivas, em um certo tom "enxuto", impessoal, sem detalhamento, com ausência de adjetivos e advérbios. É verdade que nem todo resumo traz em sim mesmo e de idêntica maneira todas as convençôes previstas pelo gênero: em alguns falta a conclusão da pesquisa; em outros, falta o percurso metodológico, ainda em outros, pode ser encontrado um estilo mais narrativo.

De todo modo, pode-se estabelecer a partir de uma certa ordenação de resumos uma rede formada por diferentes elos ligados a partir do mesmo suporte material que os abriga, pela opção teórica manifesta, pelo tema que anuncia, pelo objetivo explicitado da pesquisa, pelo procedimento metodológico adotado pelo pesquisador. Um conjunto de resumos organizados em torno de uma determinada área do conhecimento (Alfabetização, Leitura, Formação do Professor, Educação Matemática, por exemplo) pode nos contar uma História de sua produção acadêmica. Mas, é necessário pensar que nesta História foram considerados alguns aspectos dessa produção e que nela há certas limitaçôes.

Deve-se reconhecer que os resumos oferecem uma História da produção acadêmica através de uma realidade constituída pelo conjunto dos resumos, que não é absolutamente a mesma possível de ser narrada através da realidade constituída pelas dissertaçōes de mestrado e teses de doutorado, e que jamais poderá ser aquela narrada pela realidade vivida por cada pesquisador em sua pesquisa. Os resumos das pesquisas analisadas contam uma certa realidade dessa produção. Haverá tantas histórias sobre a produção acadêmica quantos resumos (de uma mesma pesquisa) forem encontrados. Nesse momento, estamos refletindo que certos indícios podem ser diferentes quando trazem resumos diferentes referentes a uma mesma pesquisa. Uma palavra excluída, substituída ou acrescentada a qualquer um dos resumos pode permitir que cada leitor faça uma 
apropriação diferente daquele texto, pode conduzi-lo a uma direção não prevista, pode confundi-lo na opção por um ou por outro resumo com o objetivo de escrever aspectos da produção acadêmica de uma certa área do conhecimento, pode ser responsável pela frustração do leitorpesquisador quando buscar o original.

Por outro lado, um pesquisador jamais terá controle sobre seu objeto de investigação ao tentar delimitar seu corpus para escrever a história de determinada produção. Ou melhor, é ilusório pensar que, se tomar apenas os resumos encontrados no CD-ROM da ANPED, o pesquisador estará escrevendo a História da produção acadêmica da Educação sobre determinada área, no país. Ele estará, quando muito, escrevendo uma das possíveis Histórias, construída a partir da leitura desses resumos.

Além disso, o fato do resumo ser considerado um gênero do discurso da esfera acadêmica relativamente neutro e estável, que informa objetivamente um leitor, que busca desencadear uma única leitura, não impede o pesquisador do "estado da arte" de experimentar uma outra, diferente daquela prevista pelo autor e editor, daquela que normalmente faz um pesquisador, ao lidar com os resumos, na investigação da produção de uma área de conhecimento. Ele pode surpreender-se entendendo cada resumo como único e individual porque produzido em determinadas condições de produção e de leitura, que pressupõem outro leitor, outra finalidade.

Assim é que o resumo permite outras descobertas, se lido e interrogado para além dele mesmo, numa prática de leitura mais "livre", aquela fora dos preceitos previstos pelo autor. Mas, ao mesmo tempo, a leitura de cada resumo é "freada" pelas pistas, indícios deixados nele pelo autor, que conduzem a uma e não outra compreensão de todo e qualquer resumo.

Ainda, podemos dizer que a História de certa produção, a partir dos resumos das pesquisas, não oferece uma compreensão linear, uma organização lógica, seqüencial do conjunto de resumos. Entre os textos há lacunas, ambigüidades, singularidades, que são preenchidas pela leitura que o pesquisador faz deles. Então, a História da produção acadêmica é aquela proposta pelo pesquisador que lê. Haverá tantas Histórias quanto leitores houver dispostos a lê-las.

Aceitar tais afirmações e considerações exige que o pesquisador, ao lidar com seu objeto de leitura e análise - os resumos -, não busque apenas uma relação do resumo com a pesquisa, metonimicamente (uma 
parte que representa o todo), nem uma relação de fidedignidade do resumo em relação à pesquisa a qual se refere e, muito menos, uma relação exclusivamente de contigüidade. Cada resumo deve ser lido e analisado numa relação de dependência com o trabalho na íntegra, mas também enquanto realidade relativamente independente, produto de uma tensão construída na continuidade e na ruptura com o trabalho que lhe dá origem, numa relação dialética entre os gêneros, entre as condições de sua produção e práticas discursivas.

Por último, ao interrogar os resumos como elos de uma cadeia de comunicação verbal da esfera acadêmica, como textos a suscitar respostas e que respondem a outros que o antecedem e o sucedem, apoiando-se na noção bakhtiniana de cadeia verbal, chega-se a outras considerações.

É possível ler em cada resumo e no conjunto deles outros enunciados, outros resumos, outras vozes, e perceber a presença de certos aspectos significativos do debate sobre determinada área de conhecimento, em um determinado período. A possibilidade de leitura de uma História pelos resumos que sabemos não poder ser considerada a única, tampouco a mais verdadeira e correta, mas aquela proposta pelo pesquisador do "estado da arte"; pode ainda ser resultado da compreensão das marcas deixadas pelos autores/editores em cada resumo e do estabelecimento de relações de cada um deles (resumo) com outros, e também com uma bibliografia que extrapola a da produção de dissertaçōes e teses.

Essa leitura possível dos resumos não se constrói linearmente ou em uma simples cadeia. Cada resumo, mais do que ligado àqueles que o antecedem e o sucedem, traz no interior de si mesmo vozes de outros enunciados. A imagem que melhor pode explicar é a de rede e não de cadeia. Rede de vários fios que se cruzam, que se rompem, que se unem, que se questionam dependendo do ponto que se estabelece como partida em cada texto.

Recebido em agosto de 2001 e aprovado em maio de 2002.

\section{Nota}

1. Caso o leitor se interesse, ver a respeito os resumos referentes aos trabalhos de Santos (1993), que foram localizados no CD-ROM ANPED (1996) e CD-ROM da UfSCAR; os de Pereira (1990), localizados na própria tese de doutorado e no Catálogo impresso da PUC-RJ; e os de Perez (1990), identificados no CD-ROM ANPED e no CD-ROM Unibibli. A escolha por esses resumos foi orientada pelo fato deles apresentarem mais de um texto referente a uma mesma pesquisa, porém encontrados em fontes diferentes, suportes de textos diferentes. 
Referências bibliográficas

ANDRÉ, M.; ROMANOWSKI, Joana P. Estado da arte sobre formação de professores nas dissertações e teses dos programas de pós-graduação das universidades brasileiras, 1990 a 1996. Programa e Resumos da 22a Reunião Anual da Associação Nacional de Pós-Graduação e Pesquisa em Educação (Anped), Caxambu-MG, 1999.

ANPED. Associação Nacional Pós-Graduação e Pesquisas em Educação, São Paulo, 1996. CD-ROM.

BAKHTIN, M. Questôes de Literatura e de Estética. A teoria do romance. São Paulo: UNEsP, 1988.

. Estética da criação verbal. São Paulo: Martins Fontes, 1997.

BRZEZINSKI, Iria; GARRIDO, Elsa. Estado da arte sobre a formação de professores nos trabalhos apresentados no GT 8 da ANPED, 1990-1998. Programa e Resumos da 22a Reunião Anual da Associação Nacional de Pós-Graduação e Pesquisa em Educação (ANPED), Caxambu-MG, 1999.

CHARTIER, R. História cultural - Entre práticas e representaçôes. Rio de Janeiro: Bertrand, 1996.

. A aventura do livro do leitor ao navegador. São Paulo: UnESP, 1998.

. (Org). Práticas de leitura. São Paulo: Estação Liberdade, 1996.

- A ordem dos livros: Leitores, autores e bibliotecas na Europa entre os séculos XIV e XVIII. Brasília: Editora da UNB, 1994.

CHAUÍ, M. A universidade operacional. Revista da ADUNICAMP, Campinas, ano $1, \mathrm{n}^{\circ} 1$, jun. 1999.

FERREIRA, Norma S. A. Pesquisa em leitura: Um estudo dos resumos de dissertações de mestrado e teses de doutorado defendidas no Brasil, de 1980 a 1995. Tese de doutorado, Faculdade de Educação da UniCAMP. Campinas, 1999.

FIORENTINI, Dario. Rumos da pesquisa brasileira em Educação Matemática. $\mathrm{O}$ caso da produção científica em cursos de Pós-Graduação. Tese de doutorado, Faculdade de Educação da Unicamp. Campinas, 1994. 
FRACALANZA, H. O que sabemos sobre os livros didáticos para o ensino de ciências no Brasil. Tese de doutorado, Faculdade de Educação da UnICAMP. Campinas, 1992.

GARRIDO, E. A técnica close e a compreensão da leitura: Investigação em textos de estudos sociais para a $6^{\text {a }}$ série. Dissertação de mestrado, USP. São Paulo, 1979.

GOULEMOT, J. Mani. "Da Leitura como produção de sentidos". In: Chartier, R. (Org.), Práticas de Leitura, São Paulo: Estação Liberdade, 1996.

KAUCHAKJE, S. Movimentos sociais na academia; Um olhar sobre as teses e dissertações produzidas na UNICAMP e USP entre 1970-1995. Tese de doutorado, Faculdade de Educação da UniCamp. Campinas, 1997.

MEGID, Jorge Neto. Tendências da pesquisa acadêmica sobre o ensino de ciências no nível fundamental. Tese de doutorado, Faculdade de Educação da Unicamp. Campinas, 1999.

PEREIRA, Marisa de M. S. Bernardes. As estratégias de leitura em crianças recém-alfabetizadas. Pontifícia Universidade Católica do Rio de Janeiro, Instituto de Letras e Artes. Rio de Janeiro, 1990.

PEREZ, Isilda L. Currículo, leitura, literatura: Das possíveis leituras às muitas indagações. Uma visão da rede municipal de ensino de São Paulo. Dissertação de mestrado, Faculdade de Educação da USP. São Paulo, 1990.

SANTOS, Patrícia L. Representações sobre o comportamento de leitura de crianças e adolescentes na visão das mães. Dissertação de mestrado, Centro de Educação e Ciências Humanas da Universidade Federal de São Carlos (UfSCAR). São Carlos, 1993.

SEVERINO, Antonio J. Metodologia do trabalho cientifico. São Paulo: Cortez \& Moraes, 1986.

SOARES, M. Alfabetização no Brasil - O Estado do conhecimento. Brasília: INEP/MEC, 1989.

TIMPONI, A. dos Santos. Estudo de Criatividade no Brasil: Análise de teses/dissertações em Psicologia e Educação. Dissertação de mestrado, Faculdade de Educação da Unicamp. Campinas, 1995.

UNIBIBLI. Catálogo coletivo de livros, teses e publicações seriados, USP, UniCAMP, UnESP. 3a ed. São Paulo, maio 1996. CD-ROM. 